\title{
Biochemical markers of neurologic injury in cardiac surgery: The rise and fall of $\mathrm{S} 100 \mathrm{\beta}$
}

Jarle Vaage, MD, PhD, FETCS ${ }^{\mathrm{a}}$

Russell Anderson, MD, $\mathrm{PhD}^{\mathrm{b}}$

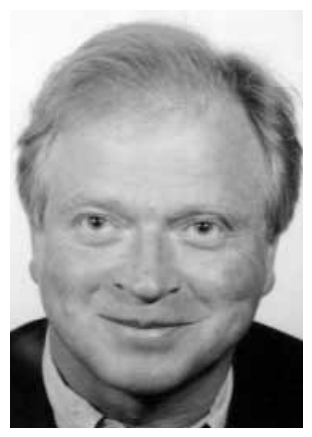

Dr Vaage

See related article on page 1019 .
From the Departments of Thoracic Surgery ${ }^{a}$ and Thoracic Anaesthetics and Intensive Care, ${ }^{\mathrm{b}}$ Karolinska Hospital, Stockholm, Sweden.

Received for publication July 3, 2001; accepted for publication July 13, 2001.

Address for reprints: Jarle Vaage, MD, Department of Thoracic Surgery, Karolinska Hospital, S-17176, Stockholm, Sweden (Email: jarle.vaage@ks.se).

J Thorac Cardiovasc Surg 2001;122:853-5

Copyright (C) 2001 by The American Association for Thoracic Surgery

$0022-5223 / 2001 \$ 35.00+0 \quad \mathbf{1 2 / 1 / 1 1 9 0 5 5}$

doi: $10.1067 / \mathrm{mtc} .2001 .119055$

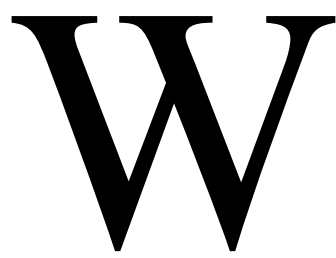

ith the change in patient population toward older and sicker patients undergoing cardiac surgery, neurologic injury has emerged as perhaps the most important perioperative complication, and its frequency increases exponentially with increasing age. ${ }^{1}$ Particular attention has been paid to the role of cardiopulmonary bypass per $\mathrm{se}^{2}$ and thromboembolization from the ascending aorta. ${ }^{3}$ However, neurologic injury is not limited to only stroke and coma ${ }^{1}$; increasingly there is a focus on the more subtle neurocognitive dysfunction and its consequences on quality of life. ${ }^{4,5}$

The majority of cases of gross neurologic injury do not represent a diagnostic problem, as at the time of diagnosis the injury is usually manifest and irreversible. Neurocognitive dysfunction, however, is less accessible for quantification, which requires time-consuming neuropsychologic testing. With only a few exceptions, such testing has been unavailable for the cardiac surgeon. Prompted by the increasing awareness of neurologic injury, as well as the emergence of minimally invasive cardiac surgery, there is at present an increasing interest in cognitive testing. However, such testing will remain a research method and not available in everyday clinical practice because of the time and manpower it consumes.

A biochemical marker in the blood of the patients-"a troponin of the brain"would represent a revolution in the investigation and diagnosis of neurologic injury in cardiac surgery. A serum marker could potentially identify which aspect(s) of cardiac surgery are responsible for cognitive dysfunction and evaluate the efficacy of alternative surgical techniques. Additionally, if marker concentrations during or directly after surgery could be related to cognitive dysfunction or shown to predict gross neurologic injury that became clinically evident after some hours (or days), then potentially neuroprotective interventions might be indicated.

The ideal biochemical marker should have the following properties:

1. Central nervous specificity

2. Rapid and significant release into blood after injury, preferably within minutes

3. Elimination within a few hours

4. Rapidly and readily obtainable assay results

5. Predictability of serious injury from an early sample, eg, at the end of surgery

6. Relationship of marker concentration to the degree of injury, quantifying the full range from subtle cognitive deficits to gross injury

7. Inexpensive

During the past two decades a variety of substances have been suggested as possible biochemical markers of brain injury, such as adenylate kinase, creatinine phosphokinase isoenzyme BB, lactate, myelin basic protein, S100 $\beta$, and neuron-specific enolase. ${ }^{6}$ Recently, glial fibrillary acidic protein has been added to this list, ${ }^{7}$ but its potential role is unknown. Most of these substances have methodologic problems: for instance, adenylate kinase and lactate have to be sampled directly from cerebrospinal fluid, and creatinine phosphokinase isoenzyme BB lacks brain specificity. The value of neuron-specific enolase was also recently shown to be doubtful 
because of its association with hemolysis caused by destruction of erythrocytes. ${ }^{8}$

S100 $\beta$ appeared to fulfill many of the above criteria of an ideal marker. ${ }^{6,9,10}$ Serum $S 100 \beta$ increases not only after cardiac surgery, but also in Alzheimer disease, Down syndrome, minor and major head injury, acute stroke, and after cardiac arrest. ${ }^{9}$ It has been suggested to be a prognostic predictor for the long-term consequences of minor head injuries and the degree of anoxic brain injury after cardiac arrest. ${ }^{9}$

Cardiac surgery causes an increase of serum $\mathrm{S} 100 \beta$ after less than an hour (ie, before cannulation), a further increase to maximum blood levels at the end of cardiopulmonary bypass, and thereafter it rapidly declines, ${ }^{6,9}$ although occasionally with a late rise. Serum $S 100 \beta$ has been correlated with age, duration of cardiopulmonary bypass, duration of aortic crossclamping, duration of deep hypothermic circulatory arrest, number of cerebral emboli during surgery, preoperative cerebrovascular complications, and preoperative renal impairment. ${ }^{9}$ The use of a filter in the arterial line or heparin-coated surfaces reduces postoperative $S 100 \beta$ levels. ${ }^{9}$ There are anecdotal reports that patients with operative cerebral injuries have higher concentrations of $S 100 \beta$ at the end of surgery. ${ }^{11,12}$ The relation of $S 100 \beta$ to neurocognitive dysfunction is controversial, but most studies do not find such a correlation.

These findings initiated the tremendous interest in S100 $\beta$, which was rapidly adopted as the marker of cerebral injury until recent findings suggested the presence of a significant noncerebral contribution. Patients operated on off-pump were shown to lack the large increased concentration seen after bypass, but an assay with increased sensitivity revealed a puzzling increase after only the prebypass surgical trauma. ${ }^{13}$ Jönsson and associates ${ }^{14}$ sampled blood every hour for the first 10 hours postoperatively, detected brief elevations of $S 100 \beta$ that coincided with the time points of autotransfusion, and found a 20 -fold increase of $\mathrm{S} 100 \beta$ in the mediastinal shed blood compared with the regular blood samples. Anderson and colleagues ${ }^{15,16}$ showed that if the cardiotomy suction was replaced by a cell-saving device during surgery with cardiopulmonary bypass, the serum S100 $\beta$ concentrations during the whole perioperative period were indistinguishable from those of patients operated on offpump. S100 $\beta$ in the cell-saving reservoir blood was 10 -fold greater than the maximum serum S100 $\beta$ in patients undergoing conventional coronary artery bypass surgery with cardiopulmonary bypass using a cardiotomy suction. Pleural drainage blood from patients having a thoracotomy (no cardiopulmonary bypass) contained equally large S100 $\beta$ concentrations as blood from mediastinal drains after on-pump cardiac surgery. ${ }^{16}$ Very high levels of S100 $\beta$ were detected in blood from the surgical wounds, from bone marrow aspirate, in mediastinal fat, and in skeletal muscle-concentrations that were up to 1000 times higher than the preoperative blood concentrations. ${ }^{16}$ Brain specificity was not improved by separate analysis of the two dimer subgroups that comprise $\mathrm{S} 100 \beta$ as it is commercially assayed. ${ }^{16}$ Both dimers appear in serum after surgery and both arise from extracerebral sources, especially traumatized fat and muscle tissue.

Hopes to use serum $S 100 \beta$ to screen patients who have had head trauma are clouded by the finding that even trauma patients without head injury have increased concentrations of serum S100 $\beta$, particularly after bone fractures, but even after limited soft tissue trauma and burns. These noncerebral contributions limit the usefulness of serum $\mathrm{S} 100 \beta$ in neurosurgery. ${ }^{17}$ Serum S100 $\beta$ increases seen after accidental or only surgical trauma (such as after off-pump surgery or on-pump surgery without a cardiotomy reservoir) may be completely explained, although a cerebral contribution cannot be excluded, by capillary and lymphatic uptake into the circulation of the small (11-kd) S100 monomer due to the high concentration difference between mediastinal blood and the bloodstream. ${ }^{16}$

Consequently, extracerebral sources of $S 100 \beta$ make the interpretation of the early $\mathrm{S} 100 \beta$ blood concentrations difficult, and no valid conclusions concerning neurologic injury in cardiac surgery can be drawn from the early release. To a large extent, the correlations previously detected for $\mathrm{S} 100 \beta$ levels after cardiopulmonary bypass can be related to the use of the cardiotomy suction: a longer operation or more complicated patient population means that more blood is suctioned from the mediastinum with increased return of mediastinal blood to the circulation, and thus the higher serum S100 $\beta$ concentration. All previous data on S100 $\beta$ should be reevaluated in light of this knowledge. The similarity of release between on-pump (when a cell saving system is used) and off-pump surgery suggests that cardiopulmonary bypass per se does not release $S 100 \beta .{ }^{15,16}$ These data imply that the early sampling of $\mathrm{S} 100 \beta$ is useless in detecting neurologic damage after conventional cardiac surgery using cardiopulmonary bypass because of the high background noise of $\mathrm{S} 100 \beta$ release from extracerebral sources. Late increases in serum $\mathrm{S} 100 \beta$, after 24 to 48 hours, have been related to perioperative cerebral complications like stroke, delayed awakening, and confusion. ${ }^{9,12}$ Unfortunately, this is neither helpful nor really interesting, because at this stage the brain injury is already manifest and irreversible and may be quantified in other, probably more precise ways. The potentially most interesting use of the serum $S 100 \beta$ concentration would have been a detectable contribution from the brain at or immediately after the operation.

Two possibilities for the use of early $\mathrm{S} 100 \beta$ release exist: 1. Can an early high level of serum $S 100 \beta$ predict that a neurologic injury has occurred? This is probably only possible if the cardiotomy reservoir has not been used. The contributions from surgical trauma are smaller, but as cardiopulmonary bypass makes no distinguishable 
addition, any correlation with cognitive dysfunction is below the level of detection.

2. Sampling of cerebrospinal fluid for measurements of S100 $\beta$ may avoid the above problems, although a spinal tap may create additional problems. Spinal fluid drainage presents a unique opportunity to compare cerebrospinal fluid and blood levels of S100ß.

In this issue of the Journal, Kunihara, Shiiya, and Yasuda $^{18}$ compared values in serum and in cerebrospinal fluid of patients undergoing surgery for thoracoabdominal aneurysms. The number of patients in each group is small, but the study shows higher sensitivity and earlier release of $\mathrm{S} 100 \beta$ into the cerebrospinal fluid when spinal injury occurred. More such studies are needed to investigate whether S100 $\beta$ has any place at all as an early marker of neurologic injury in cardiovascular surgery. At the present time, using serum $S 100 \beta$ concentrations immediately after the end of bypass as a marker of neurologic injury is not acceptable if a cardiotomy suction has been used. In addition, any tissue damage will limit its usefulness, particularly in diagnosing the subtle changes of greatest interest.

\section{References}

1. Roach GW, Kanchuger M, Mangano CM, Newman N, Nussmeier N, Wolman R, et al. Adverse cerebral outcomes after coronary bypass surgery. N Engl J Med. 1996;335:1857-63.

2. Arrowsmith JE, Grocott HP, Reves JG, Newman MF. Central nervous system complications of cardiac surgery. Br J Anaesth. 2000;84:378-93.

3. Vaage J, Jensen U, Ericsson A. Neurologic injury in cardiac surgery: aortic atherosclerosis emerges as the single most important risk factor. Scand Cardiovasc J. 2000;34:550-7.

4. Murkin JM, Martzke JS, Buchan AM, Bentley C, Wong C. A randomized study of the influence of perfusion technique and $\mathrm{pH}$ management strategy in 316 patients undergoing coronary artery bypass surgery. II. Neurologic and cognitive outcomes. J Thorac Cardiovasc Surg. 1995;110:349-62.
5. Newman MF, Kirchner JL, Phillips-Bute B, Gaver V, Grocott H, Jones $\mathrm{RH}$, et al. Longitudinal assessment of neurocognitive function after coronary artery bypass surgery. $N$ Engl J Med. 2001;344:395-402.

6. Johnsson P. Markers of cerebral ischemia after cardiac surgery. $J$ Cardiothorac Vasc Anesth. 1996;10:120-6.

7. Missler U, Wiesman M, Wittmann G, Magerkurth O, Hagenström H. Measurement of glial fibrillary protein in human blood: analytical method and preliminary clinical results. Clin Chem. 1999;45:138-41.

8. Johnsson P, Blomquist S, Lührs C, Malmkvist G, Alling C, Solem J$\mathrm{O}$, et al. Neuron specific enolase increases in plasma during and immediately after extracorporeal circulation. Ann Thorac Surg. 2000;69:750-4.

9. Shaaban M, Harmer M, Vaughan R. Serum S100 protein as a marker of cerebral damage during cardiac surgery. Br J Anaesth. 2000;85: 287-98.

10. Kato K, Kimura S. S100 (alpha alpha) protein is mainly located in the heart and striated muscles. Biochem Biophys Acta. 1984;842:146-50.

11. Blomquist S, Johnsson P, Lührs C, Malmkvist G, Solem J-O, Alling C, et al. The appearance of $\mathrm{S} 100$ protein in serum during and immediately after cardiopulmonary bypass surgery: a possible marker for cerebral injury. J Cardiothorac Vasc Anesth. 1997;11:699-703.

12. Lemaire SA, Bhama JK, Schmittling ZC, Oberwalder PJ, Köksoy C, Raskin SA, et al. S100 $\beta$ correlates with neurologic complications after aortic operation using circulatory arrest. Ann Thorac Surg. 2001;71: 1913-9.

13. Anderson R, Hansson L-O, Vaage J. Release of S100 $\beta$ during coronary artery bypass grafting is reduced by off-pump surgery. Ann Thorac Surg. 1999;67:1721-5.

14. Jönsson H, Johnsson P, Alling C, Bäckström M, Bergh C, Blomquist S. S100 $\beta$ after coronary surgery: release pattern, source of contamination, and relation to neuropsychological outcome. Ann Thorac Surg. 1999;68:2202-8

15. Anderson R, Hansson L-O, Liska J, Settergren G, Vaage J. The effect of the cardiotomy suction on the brain injury marker S100 $\beta$ after cardiopulmonary bypass. Ann Thorac Surg. 2000;69:847-50.

16. Anderson R, Hansson L-O, Nilsson O, Liska J, Settergren G, Vaage J. Increase in serum S100A1-B and S100BB during cardiac surgery arises from extracerebral sources. Ann Thorac Surg. 2001;71:1512-7.

17. Anderson R, Hansson L-O, Dijlai-Merzoug R, Settergren G. High serum $\mathrm{S} 100 \beta$ levels for trauma patients without head injuries. Neurosurgery. 2001;48:1255-8, discussion 1258-60.

18. Kunihara T, Shiiya N, Yasuda K. Changes in S-100 $\beta$ proteins in the cerebrospinal fluid after thoracoabdominal aortic surgery. $J$ Thorac Cardiovasc Surg. 2001;122:1019-20. 